\title{
Can Mucosectomy be Always Performed in Complicated Cases of Choledochal Cysts
}

\author{
Sezen Özkisacik ${ }^{1}$, Mesut Yazici ${ }^{1}$, Canten Tataroglu ${ }^{2}$, Yelda Ozsunar ${ }^{3}$, Harun Gürsoy ${ }^{1}$ \\ ${ }^{1}$ Adnan Menderes University, Medical Faculty, Department of Pediatric Surgery, Aydin, Turkey \\ ${ }^{2}$ Adnan Menderes University, Medical Faculty, Department of Pathology, Aydin, Turkey \\ ${ }^{3}$ Adnan Menderes University, Medical Faculty, Department of Radiodiagnostic, Aydin, Turkey \\ E-mail: sozkisacik@adu.edu.tr \\ Received September 9, 2010; September 18, 2010; September 25, 2010
}

\begin{abstract}
Introduction: If the surgical dissection is too risky in choledochal cyst, mucosectomy is defined as a beneficial technical method in the literature. To discuss in this manner, we present this case. Case: 9 years old girl was referred to our clinic due to multipl stones in the gallbladder. History and physicial examination could not be performed effectively because of her cerebral palsy. Ultrasonography showed choledochal cyst containing multipl stones. MR cholangiography showed multipl stones in the dilated choledochus. During the dissection, the cyst appeared extremely adherent to the adjacent structures and cyst wall was so thin and transparent. The mucosectomy was not thought to be a good option to carry out for this case. For this reason, cyst was totally excised. Discussion: The preferred method for choledochal cyst is total cyst excision and Roux-en Y hepaticoenterostomy. When the dissection is unsafe to perform, posterior wall mucosectomy may be performed. However, like in our case, when the diagnosis is delayed, the cyst wall may become too thin and may be attached very strongly to the adjacent structures. So, mucosectomy is impossible and full layer total cyst excision remains as the only alternative in spite of its high risks.
\end{abstract}

Keywords: Mucosectomy, Choledoch, Cyst

\section{Introduction}

Choledochal cysts are rare congenital anomalies of the biliary tree [1]. Since every piece of unresected remains of the cystic wall is associated with malignancies [2], the method of choice for the treatment of choledochal cysts in children is total resection and Roux-en-Y (RY) hepaticoenterostomy to prevent carcinogenesis of biliary duckts [3]. If there is inflammation in the cystic wall, if the cyst is excessively inflated and if it is adhered to surrounding tissue excessively, total resection may not be possible. Since surgical resection of the posterior wall may cause excessive risk in such cases, excision of the cyst mucosa (mucosectomy), a technique which facilitates the operation and renders excision more successful, has been described [4,5].

We will present a case of choledochal cyst found to have no specific findings, but difficulty in orientation due to cerebral palsy on history and physical examination and treated with full thickness total resection.

\section{Case}

A nine-year-old girl was referred to our center for multiple calculi in her gallbladder detected on abdominal ultrasonography (USG) and computed tomography (CT). On history, she frequently presented with restlessness to several health centers; however, it turned out that effective examination could not be performed and that history could not be taken because she had cerebral palsy since she was two years old.

In our emergency department, physical examination could not be carried out properly. Direct abdominal x-ray taken when the patient was standing showed two air-fluid levels on the right upper quadrant. Therefore, abdominal USG was repeated and then magnetic resonance (MR) cholangiography was performed. USG and MR cholangiography demonstrated a choledochal cyst containing multiple calculi (Figure 1). The patient underwent operation. On intraoperative USG and cholangiography, the cyst was about 7-8 $\mathrm{cm}$ in length and $5 \mathrm{~cm}$ in width and connected to the pancreas via $1.5 \mathrm{~cm}$ - 
common bile duct and intrahepatic bile ducts were dilated (Figure 2). While we were removing the cyst, the cyst wall was quite thin and so much adhered to the surrounding tissue that surgical dissection was impossible (Figure 3). We thought that dissection of the cyst wall is riskier in such cases and decided to perform mucosectomy. However, the cyst wall was too thin to allow mucosectomy and cystic fluid became apparent. Due to all these complexities, we had to perform a total removal of the gallbladder and the cyst: we carried out total cyst excision and Roux-en Y cholechojejunostomy. On day 14 after the operation, no complications developed and the patient was discharged. Pathological examination revealed that the cyst wall was $1 \mathrm{~mm}$ in thickness and its mucosa was occasionally shed (Figure 4).

\section{Discussion}

Many treatment alternatives have been described for choledochal cysts and the alternative of choice at present is total excision of the cyst and extrahepatic bile ducts and Roux-en Y choledochojejunostomy [6]. Although such complications as recurrent cholangitis, intrahepatic bile duct stones, pancreatitis, intrahepatic calculi and malignancy may appear [3], no complications occurred during one year follow-up of this patient.

If there is excessive adhesion between a cyst and surrounding tissues at the time of total excision of the cyst and bile ducts, dissection can be very difficult. Actually, if the diagnosis is delayed, there may be an increase in adhesions. Cyst mucosectomy is recommended for the treatment of such cases in order to decrease surgical risk and complications. It is claimed that this method prevents postoperative pancreatitis and/or stone formation due to residual cyst [5].

However, as in the case presented here, when the cyst wall became too thin and its mucosa was shed, mucosectomy can be technically impossible. Therefore, full

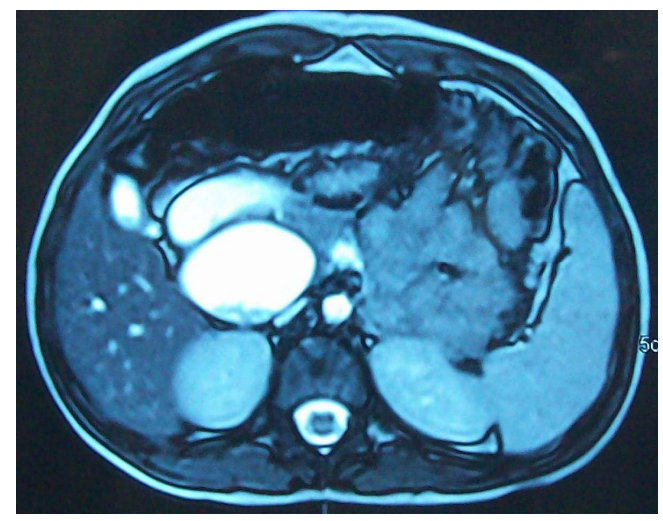

Figure 1. MR cholangiography demonstrated a choledochal cyst containing multiple calculi.

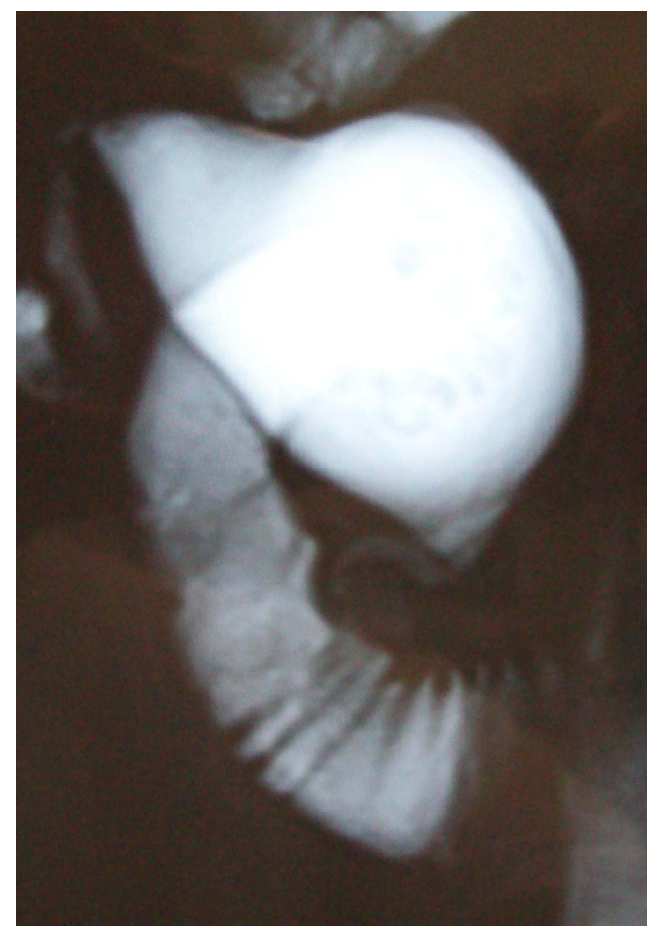

Figure 2. Intraoperative cholangiography, the cyst was about 7-8 cm in length and $5 \mathrm{~cm}$ in width and connected to the pancreas via $1.5 \mathrm{~cm}$-common bile duct.

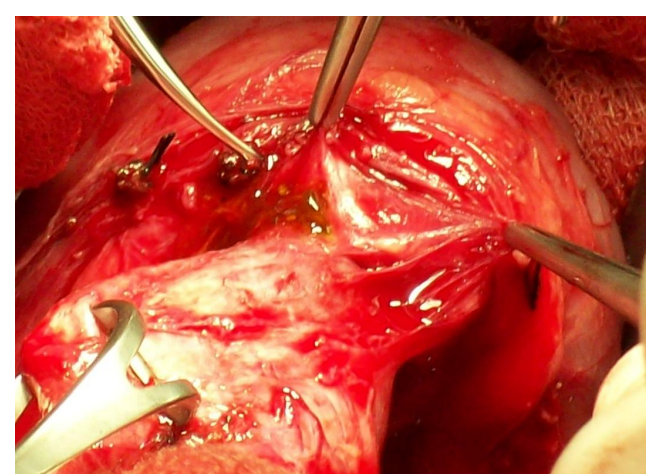

Figure 3. The cyst wall so much adhered to the surrounding tissue.

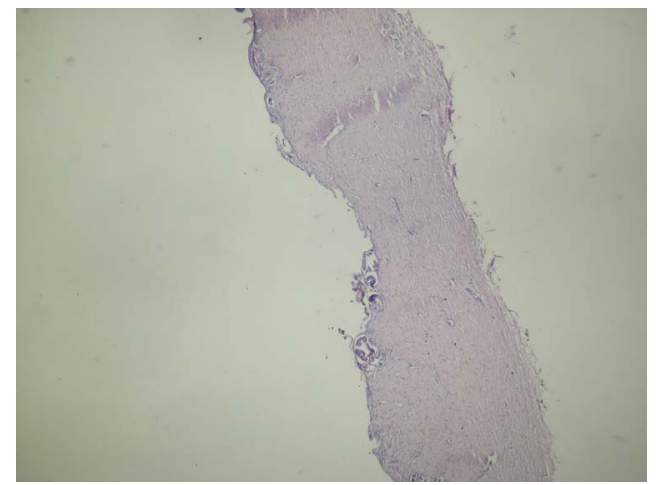

Figure 4. Pathological image, the cyst wall was $1 \mathrm{~mm}$ in thickness and its mucosa was occasionally shed. 
thickness total excision can be the only alternative left despite high surgical risk.

\section{References}

[1] D. H. Park, M. H. Kim, S. K. Lee, S. S. Lee, J. S. Choi, Y. S. Lee, D. W. Seo, H. J. Won and M. Y. Kim, "Can MRCP Replace the Diagnostic Role of ERCP for Patients with Choledochal Cysts?,” Gastrointestinal Endoscopy, Vol. 62, No. 3, 2005, pp. 360-366. doi:10.1016/j.gie.2005.04.026

[2] S. Kobayashi, T. Asano, M. Yamasaki, T. Kenmochi, T. Nakagohri and T. Ochiai, "Risk of Bile Duct Carcinogenesis after Excision of Extrahepatic Bile Ducts in Pancreaticobiliary Maljunction,” Surgery, Vol. 126, No. 5, 1999, pp. 939-944. doi:10.1016/S0039-6060(99)70036-X

[3] A. Yamataka, K. Ohshiro, Y. Okada, Y. Hosoda, T. Fujiwara, S. Kohno, M. Sunagawa, S. Futagawa, N. Sa- kakibara and T. Miyano, "Complications after Cyst Excision with Hepaticoenterostomy for Choledochal Cysts and Their Surgical Management in Children versus Adults," Journal of Pediatric Surgery, Vol. 32, No. 7, 1997, pp.1097-1102. doi:10.1016/S0022-3468(97)90407-3

[4] P. Puri and M. E. Höllwarth, Pediatric Surgery, 2006. pp. 371-386.

[5] S. A. Hay, "Laparoscopic mucosectomy for large choledochal cyst,” Journal of Laparoendoscopic \& Advanced Surgical Techniques, Vol. 18, No. 5, 2008, pp.783-784. doi:10.1089/lap.2008.0008

[6] N. Urushihara, K. Fukumoto, H. Fukuzawa, M. Tani, T. Matsuoka, K. Suzuki, S. Kawashima and S. Hasegawa, "Hepaticojejunostomy and Intrahepatic Cystojejunostomy for Type IV-A Choledochal Cyst,” Journal of Pediatric Surgery, Vol. 42, No. 10, 2007, pp.1753-1756. doi:10.1016/j.jpedsurg.2007.06.012 